\title{
Depth and region dependence of $b$-value for micro-aftershocks of the May 12th, 2008 Wenchuan earthquake and its tectonic implications*
}

\author{
Mei Feng* Meijian An Lin Zhao and Jizhong Zhang \\ Institute of Geomechanics, Chinese Academy of Geological Sciences, Beijing 100081, China
}

\begin{abstract}
Micro-aftershocks with magnitude range of 1.5-4 around the Wenchuan earthquake epicenter, the southern part of the Longmenshan fault zone, exhibit good frequency-magnitude linear relationships, thus enabling $b$-value analysis. The average $b$-value for micro-aftershocks of $M 1.5-4$ from July to December of 2008 in our local study region is about 0.88 , similar to the $b$-value for all aftershocks of M3.0-5.5 from May, 2008 to May, 2009 along the whole Longmenshan fault zone. The similarity between the local and regional $b$-values possibly indicates that the southern part of the Longmenshan fault zone has similar seismogenic environment to the whole Longmenshan fault zone. Alternatively, it may also imply that $b$-values derived from all events without consideration of structural variation can not discriminate local-scale tectonic information. The present study shows that the $b$-value for the Wenchuan earthquake micro-aftershocks varies with different regions. The $b$-value in southwest of the Yingxiu town is higher than that in the northeast of the Yingxiu town. The high $b$-value in the southwest part where the Wenchuan earthquake main shock hypocenter located indicates that the current stress around the hypocenter region is much lower than its surrounding area. The $b$-values are also dependent on depth. At shallow depths of $<5 \mathrm{~km}$, the $b$-values are very small ( 0.4), possibly being related to strong wave attenuation or strong heterogeneity in shallow layers with high content of porosity and fractures. At depths of $\sim 5-11 \mathrm{~km}$, where most aftershocks concentrated, the $b$-values become as high as $\sim 0.9-1.0$. At the depth below $\sim 11 \mathrm{~km}$, the $b$-values decrease with the depth increasing, being consistent with increasing tectonic homogeneity and increasing stress with depth.
\end{abstract}

Key words: micro-aftershocks; frequency-magnitude relationship; tectonic implication; Wenchuan earthquake CLC number: P315.08 Document code: A

\section{Introduction}

Gutenberg and Richter (1944) provided a general earthquake occurrence frequency-magnitude relation expressed as $\lg N=a-b M$, where $M$ is a magnitude, $N$ is the number of events in a given magnitude range, and $a$ and $b$ are constants. The slope $b$ in the linear relationship is normally called $b$-value, and a high $b$-value reflects abundance of small events with respect to larger ones. $b$-value is dependent on several factors, including stress state, tectonics and inherent physical properties of the seismogenic layer or schizosphere. Laboratory experiments (e.g., Scholz, 1968) showed that $b$-value decreases with stress increasing, and ductile rocks have

\footnotetext{
* Received 3 June 2009; accepted in revised form 10 September2009; published 10 December 2009.

^ Corresponding author. e-mail: mei_feng_cn@yahoo.com.cn
}

higher $b$-values than brittle rocks. Weak and heterogeneous regions have higher $b$-values than inactive homogeneous regions (e.g., Tsapanos, 1990).

From a global view, the $b$-value is about 1.0 if taking no account of different tectonophysics environments where the earthquakes occurred. Because stable tectonic block interior and active block boundary have constitutions of different physical properties, they are normally characterized by different $b$-values. Besides, $b$-values may differ from time to time according to tectonic stress variation. For instance, the $b$-values of the Chinese mainland in the seismic active period and seismic silent period before 2000 are $0.75 \pm 0.02$ and $0.97 \pm 0.1$, respectively (Chen et al, 2001). If we separately make statistical analysis for earthquakes occurred under different physical and tectonic conditions in local scale, we can then conversely extract local physical and tectonic in- 
formation according to the $b$-values.

Some analyses showed that the logarithms of earthquake rupture area and rupture length are proportional with earthquake magnitude (Wells and Coppersmith, 1994; Vakov, 1996; Turcotte and Schubert, 2001). Thus, the co-seismic rupture length for a large earthquake should be longer than that for small event. In general, a large earthquake can often cut the schizosphere (Scholz, 2002), but a micro-earthquake can not. Therefore, the $b$-value derived from large earthquakes normally reflects average tectonic information in a large area. Since the co-seismic deformation of micro-earthquake confines only in a small area, $b$-value derived from micro-earthquakes can show local-scale tectonic and physical properties. Therefore, the frequency-magnitude statistics of micro-seismicity are significant in a local-scale study. However, the major factor preventing a local scale $b$-value analysis is the incompleteness of micro-earthquakes in most catalogues, re- sulting in a dramatically smaller occurrence frequency of small magnitude earthquakes than predicted by the simple Gutenberg-Richter statistics law. The lack of small events may be caused by a rapid rise in scattering and seismic wave attenuation at high frequencies and these small events are out of the instrumental detection limit or only detected by a few stations in a standard array of seismometers. Therefore, in order to statistically get local-scale information from earthquakes, records from a dense seismic network are required.

After the Wenchuan earthquake occurred, we densely deployed 26 sets of short-period seismometers around the main shock epicenter region (triangles in Figure 1). These seismometers recorded a large number of high-quality micro-aftershock seismic data (circles scaled with magnitude in Figure 1). The statistics of these micro-aftershocks can hopefully give useful information on local stress state and local scale tectonics.

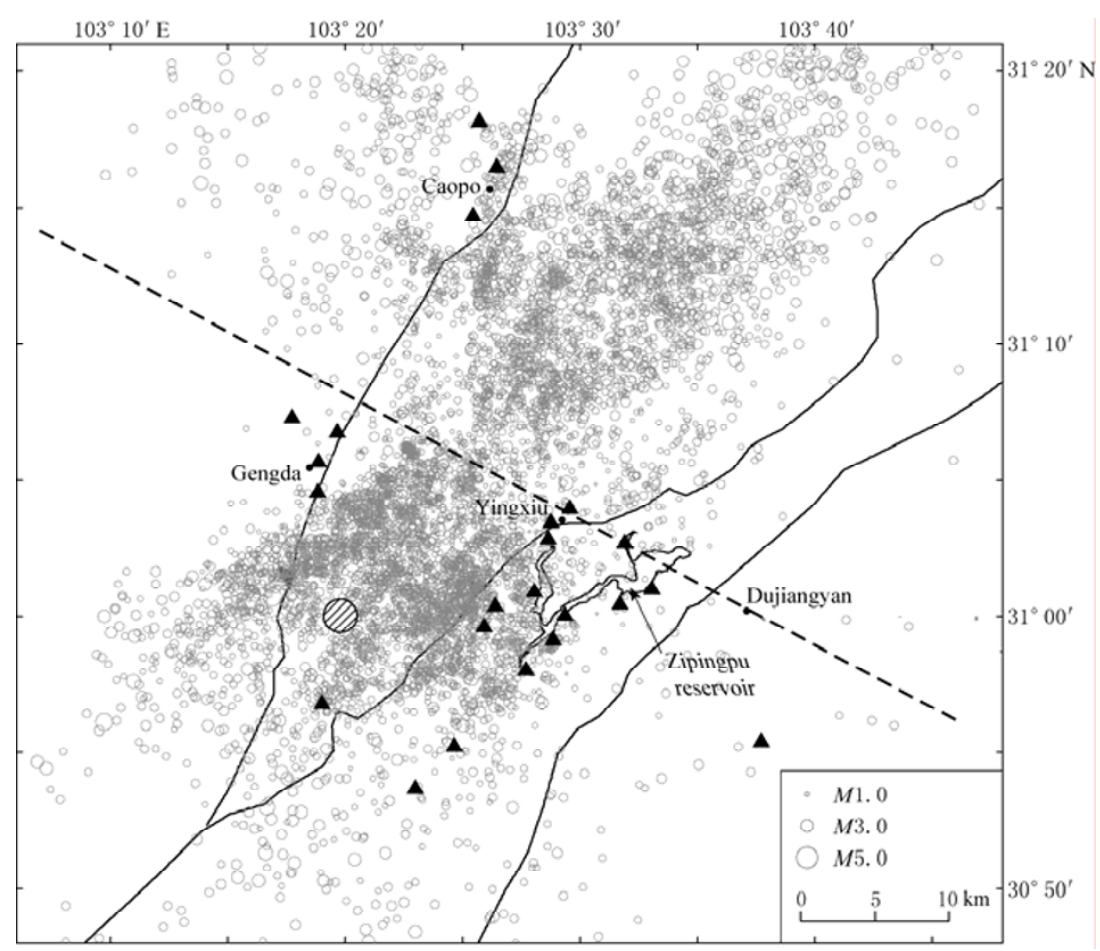

Figure 1 Seismic stations (triangles) and micro-aftershocks (circles scaled with magnitude) used in the present study. The Wenchuan earthquake main shock position is from the USGS WHDF catalogue. Solid lines are the three faults composed of the Longmenshan fault zone; the dashed line is potential fault.

\section{Data and analyses}

The micro-aftershock data used in the present study were recorded by 26 seismic stations deployed around the Wenchuan earthquake epicenter after the great earthquake occurred (triangles in Figure 1). The seismic stations are equipped with short-period Mark Products (Sercel) L-22D sensors that are appropriate to detect micro-earthquakes and with Reftek 130 digitizers to record ground velocity. An et al (2009b) previously 
processed seismic data in 108 days recorded by the same seismic network from July to October of 2008. Here we extend our analyses to the data from July to December of 2008. The hypocenters were determined using the program Hypo 71 (Lee and Lahr, 1972). To compute local earthquake magnitude using the formula and constants in Richter (1958), we routinely processed the raw seismic data by firstly deconvolving from the instrument response, then convolving with the Wood-Anderson instrument response, and finally transferring from velocity to displacement. Even though our computed magnitudes may be underestimated for moderate aftershocks since our sensors are of high frequency, the magnitudes of all $M>4$ aftershocks calculated from our dataset are similar to those in the CSN catalogue. To make our following statistic analyses more reliable, here we only considered aftershocks simultaneously recorded by at least 10 seismic stations. Totally, 7520 micro-aftershocks were retrieved (circles in Figure 1), and then routine frequency-magnitude ( $b$-value) and frequency-depth analyses are made for these events.

Figure 2 shows the frequency-magnitude relation for micro-aftershocks of the Wenchuan earthquake occurred in the study area shown in Figure 1. In this figure, micro-aftershocks of magnitude greater than 1.5 and smaller than 4.0 (i.e., $1.5<M<4.0$ ) obey well the simple Gutenberg and Richter frequency-magnitude law. Some aftershocks of $M<1.5$ may be out of our instrumental detection limit or be filtered out since only events simultaneously recorded by at least 10 seismic stations are considered. The irregular frequency-magnitude relation for aftershocks of $M>4.0$ might suggest that the time period and study area covered by our dataset are not wide enough to make statistical sense. The $b$-value (slope of the fitting line in Figure 2) of micro-aftershocks in the study area is about 0.88 . The $b$-value is similar to that

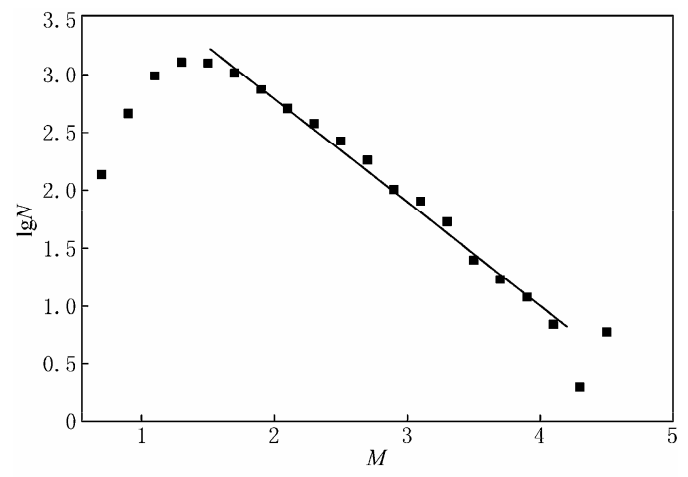

Figure 2 Frequency-magnitude relation for microaftershocks of the Wenchuan earthquake.
( 0.9) derived from events before 2006 close to the Zipingpu reservoir ( $\mathrm{Hu}, 2007)$, and to the $b$-values determined from stronger aftershocks along the whole Longmenshan fault zone using open event catalogs from provincial or national seismic networks, which will be further discussed later.

Figure 3 shows the frequency-depth relation for M1.5-4.0 micro-aftershocks of the Wenchuan earthquake. In this figure, the number of aftershock at depths smaller than $\sim 5 \mathrm{~km}$ is smaller than that at depths from $\sim 5-11 \mathrm{~km}$, while is greater than that at depths below $\sim 13 \mathrm{~km}$. An et al (2009a) found that the shallow areas down to $\sim 5 \mathrm{~km}$ close to the main shock rupture are characterized by very low seismic velocity and low seismicity and correlated these features with high content of porosity and fractures formed by tectonic activities of the Longmenshan fault zone. As static pressure above $\sim 5 \mathrm{~km}$ depth is not high enough to close the fractures or pores (Christensen, 1996), stresses in shallow saturated sediments or in fractured rocks of high content of porosity can be easily released before they accumulate to be large enough for a brittle earthquake (An et al, 2009a). This seems a reasonable explanation for why there are fewer aftershocks in the shallow depths down to $\sim 5 \mathrm{~km}$ than that in greater depths. Another possible reason to explain the low seismicity in shallow depths could be the high wave attenuation in the shallow porous/fractured layers. Figure 3 shows a significant decrease of seismicity at the depths of $\sim 13-20 \mathrm{~km}$, possibly indicating that the base of the schizosphere of the Longmenshan active fault zone close to the main shock

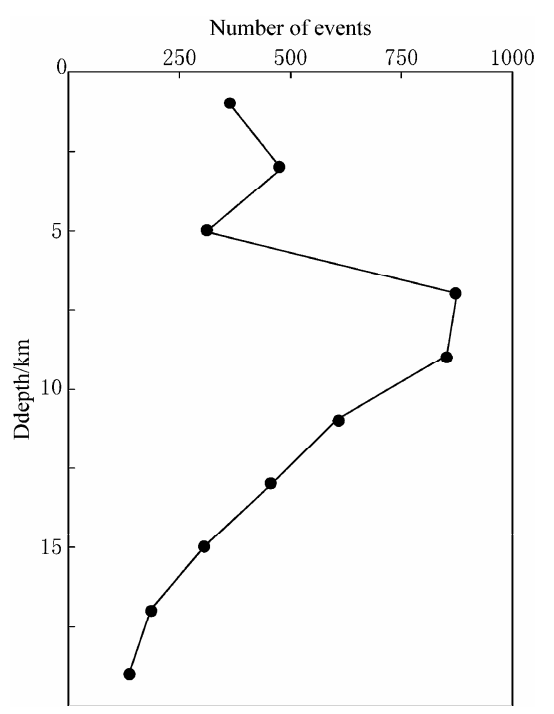

Figure 3 Frequency-depth relation for micro-aftershocks of the Wenchuan earthquake. 
is at $\sim 20 \mathrm{~km}$ in depth.

\section{Discussions}

\section{$3.1 b$-values in different regions}

An et al $(2009 b)$ revealed the deep rupture geometries around the Wenchuan earthquake epicentral region based on 3-D distribution of micro-aftershocks. Besides the three well-known NE-SW striking major faults composed of the Longmenshan fault zone, they found another NW-SE striking potential fault (dashed line in Figure 1) crossing through the Yingxiu town, and the seismicity distribution patterns to the southwest and northeast of the NW-SE potential fault are different. Thus here we made $b$-value analysis for micro-aftershocks in the northeast and southwest separately. Figure $4 \mathrm{a}$ shows the frequency-magnitude relation for the two regions. Solid triangles are statistics for the southwest region and open triangles are for the northeast region. Both regions show good frequency-magnitude linear relation for the medium magnitudes $(1.5<M<3.5)$ but have quite different $b$-values (line slopes). The $b$-value for the southwest region is $\sim 1.1$ while the slope for the northeast region is $\sim 0.69$. Considering that the number of seismic stations in northeast is smaller than that in southwest, and the focal depths for shallow earthquakes in northeast may be less reliably determined than those in southwest, we thus also

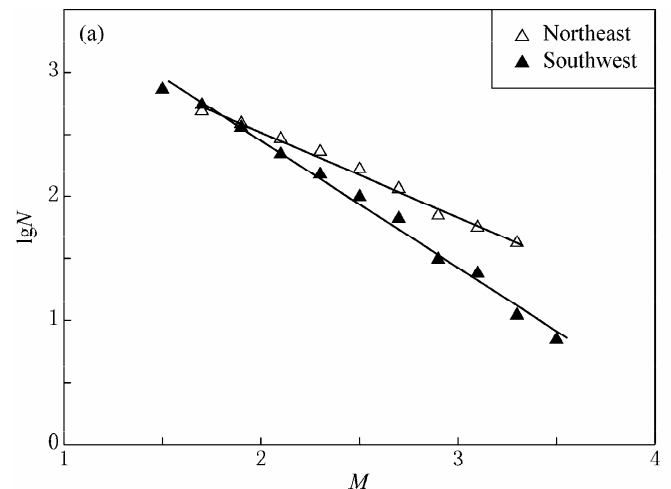

make $b$-value analysis by excluding earthquakes at depths smaller than $4 \mathrm{~km}$ (not shown here). In this case, the $b$-value is $\sim 1.05$ for the southwest region and $\sim 0.84$ for the northeast region. Both analyses with and without considering shallow earthquakes suggest an obviously higher $b$-value in the southwest region than in the northeast region. Because a higher $b$-value may reflect lower tectonic stress and weak and heterogeneous seismogenic environment, the southwest region where the main shock epicenter located may have lower tectonic stress than the northeast area. It is easy to understand since the great Wenchuan earthquake released lots of tectonic stress and the current stress around the hypocenter must be much lower than its surrounding area. The hypocenter region also must be much weaker due to the dense fractures caused by main shock rupture activities. Besides, according to the P-wave velocity tomographic model of the study area derived by An et al (2009a), the southwest region is more heterogeneous than the northeast region, consistent with our observation of higher $b$-value in the southwest region than in the northeast region. Based on the $b$-value character, the Wenchuan earthquake main shock hypocenter region (the southwest region) may have less probability occurring strong aftershocks recently than its surrounding areas (e.g., the northeast region).

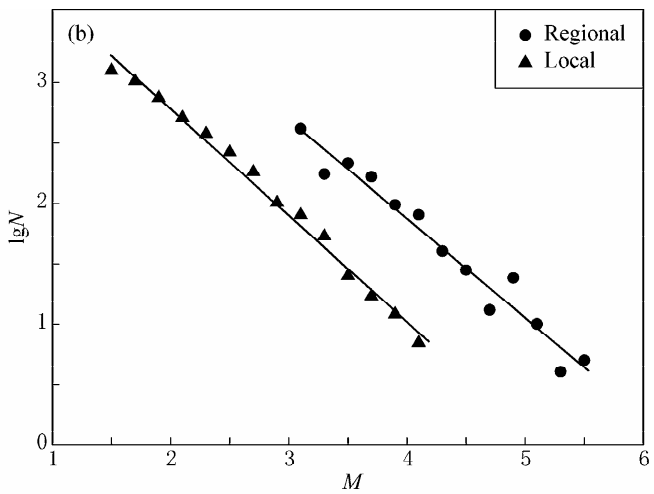

Figure 4 Frequency-magnitude relation ( $b$-values) in different regions. (a) Comparison of $b$-values between the northeast and southwest regions separated by the NW-SE striking potential fault; (b) Comparison of $b$-values between the main shock epicenter region and the whole Longmenshan fault zone.

Because the co-seismic deformation of micro-earthquake only confines within a small area and our $b$-value analysis is made for micro-aftershocks only in the southern part of the Longmenshan fault zone (Figure 1), the $b$-value primarily shows the tectonic and physical properties of the local area. To compare our results with a regional statistical analysis of the whole
Longmenshan fault zone, we also made frequency-magnitude analysis using the aftershocks before May 09, 2009 from the catalog of the Wenchuan earthquake aftershocks distributed by the Earthquake Administration of Sichuan province (www.eqsc.gov.cn). Figure $4 \mathrm{~b}$ shows the frequency- magnitude relation for our micro-aftershocks and for the regional aftershocks. 
Solid triangles are statistics for our local-scale micro-aftershocks (the same as shown in Figure 2 but excluding magnitudes with bad linear fits) and solid circles are for regional-scale aftershocks of the whole Longmenshan fault zone. Both statistics show good frequency-magnitude linear relation but with different magnitude ranges. As expected, our local-scale data covers a lower magnitude band $(1.5<M<4.0)$ than the regional-scale data $(3.0<M<5.5)$. The two fitting lines are nearly parallel, which means both local-scale and regional-scale statistics suggest a similar $b$-value. The different interceptions of the two fitting lines are caused by the different numbers of analyzed events. The similarity of the $b$-values possibly indicates that the southern part of the Longmenshan fault zone has similar seismogenic environment to the whole Longmenshan fault zone. The consistency of $b$-values derived from event catalogs with different magnitude ranges, different time periods and different regions along the same fault zone confirms the validity of our analysis based on local-scale micro-aftershocks. On the other hand, the similarity may also imply that $b$-values derived without consideration of structural difference at different region can not discriminate local-scale tectonic information.

\section{$3.2 \quad b$-values at different depths}

Besides making $b$-value analyses for different regions, the abundant micro-aftershocks enable us making $b$-value analyses at different depths. Because the focal depth of the micro-aftershocks mainly ranges from 0 to $20 \mathrm{~km}$, we carried out frequency-magnitude analyses for events from 0 to $20 \mathrm{~km}$ with every $2 \mathrm{~km}$ interval of focal depth and get $b$-values at 10 different depths. Figure 5 shows the frequency-magnitude relation plots at the 10 depths. The plots for the depths of $5-15 \mathrm{~km}$, where most micro-aftershocks concentrated, obey well the frequency-magnitude linear relation but have different line slopes. The linearity in the depths above $\sim 5 \mathrm{~km}$ and below $\sim 15 \mathrm{~km}$ becomes worse, which may be caused by the incompleteness of the data due to the low seismicity in these depths (Figures $5 \mathrm{a}, 5 \mathrm{~b}, 5 \mathrm{i}$ and $5 \mathrm{k}$ ). Figure 6 shows the compiled $b$-value variation with depths. Though the frequency-magnitude linearity is worse in depths above $\sim 5 \mathrm{~km}$, the $b$-values at these depths are remarkably lower than that at greater depths. Small $b$-values in shallow depths $(0-6 \mathrm{~km})$ were also found in California (Mori and Abercrombie, 1997), and had been suggested due to strong heterogeneity. The very low $b$-values in shallow depths of our study area may also reflect the heterogeneity of the shallow structures. At depths of $\sim 5-11 \mathrm{~km}$, the number of micro-aftershocks has a sudden increase (Figure 3 ) and the $b$-values coincidently become higher $(\sim 0.9-1.0$, in Figure $5 \mathrm{c}-5 \mathrm{f})$. For depths greater than $\sim 11 \mathrm{~km}$, the $b$-values gradually decrease with increasing depths. Decreasing of $b$-value with depth increasing have been previously found in other areas (e.g., Mori and Abercrombie, 1997). As bothpressure and temperature increase with depth, deep layers are generally more tectonically homogeneous (Mori and Abercrombie, 1997) than shallow layers
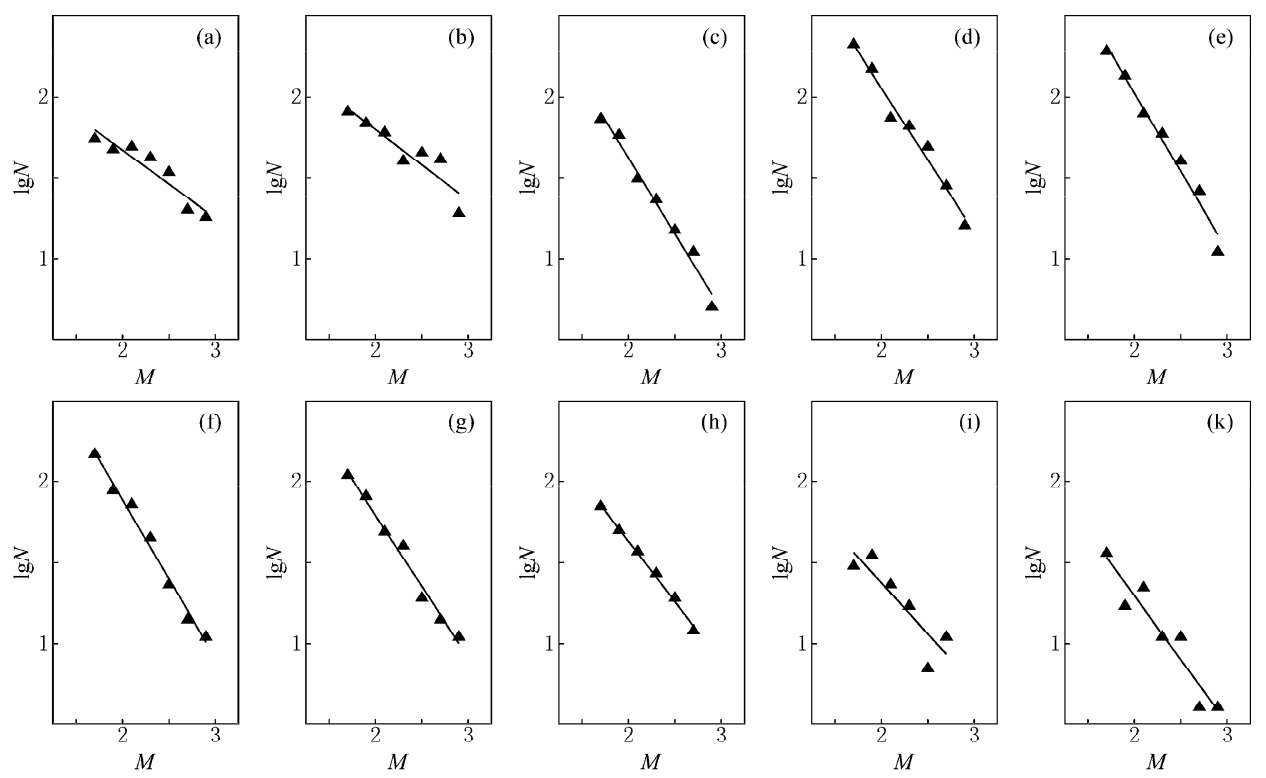

Figure 5 Frequency-magnitude relation ( $b$-values) at different depths beneath the study area. The lines are regressed from frequency-magnitude points. The depth is in the range of 0 to $20 \mathrm{~km}$ with interval of $2 \mathrm{~km}$ from (a) to (k), respectively. 


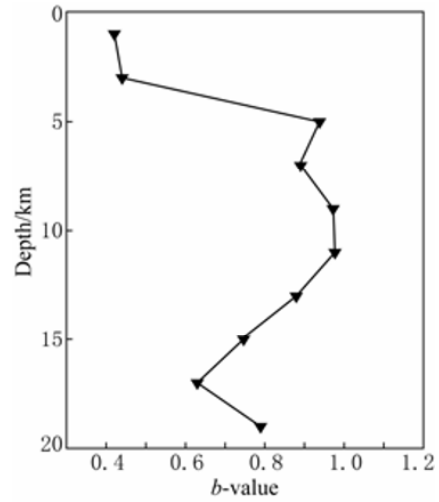

Figure $6 \quad b$-value variation with depths.

and absolute stresses normally increase with depth. Thus the lower $b$-values at greater depths may reflect tectonic homogeneity and high absolute stresses beneath our study area.

\section{Conclusions}

We made routine frequency-magnitude and frequency-focal depth analyses for micro-aftershocks of the Wenchuan earthquake occurred around the main shock hypocenter region from July to December of 2008 . The micro-aftershocks of magnitude between 1.5 and 4.0 obey well the Gutenberg and Richter frequency-magnitude law. The average $b$-value for the micro-aftershocks is $\sim 0.88$. This $b$-value is similar to that derived from larger aftershocks with magnitude of 3.0-5.5 occurred along the Longmenshan fault zone from May, 2008 to May, 2009. The similarity between the local and regional $b$-values possibly indicates that the southern part of the Longmenshan fault zone has similar seismogenic environment to the whole Longmenshan fault zone. Alternatively, it may also imply that $b$-values derived from all events without consideration of structural variation can not discriminate local-scale tectonic information.

We therefore made further $b$-value analysis for different regions of our study area. The $b$-value in the southwest of the Yingxiu town is higher than that in the northeast of the Yingxiu town. The high $b$-value in the southwest part where the Wenchuan earthquake main shock hypocenter located indicates that the current stress around the hypocenter is much lower than its surrounding region, which is quite straightforward to understand since the great Wenchuan earthquake released lots of tectonic stress around the hypocenter.
The $b$-values of micro-aftershocks around the main shock hypocenter region are also dependent on depth. At shallow depths of $\sim 0-5 \mathrm{~km}$, the $b$-value is very small, possibly being related to strong heterogeneity in shallow layers with high content of porosity and fractured materials. At depths of $\sim 5-11 \mathrm{~km}$, the $b$-values become as high as $\sim 0.9-1.0$, being consistent with sudden increase of seismicity in this depths range. At depth below $\sim 11$ $\mathrm{km}$, the $b$-values decrease with the depth increasing, possibly reflecting the gradual increase of tectonic homogeneity and absolute stresses with depth beneath the study area.

Acknowledgements This work is supported by the Basic Research Foundation of the Institute of Geomechanics, Chinese Academy of Geological Sciences (No. DZLXJK200707) and the National Natural Science Foundation of China (No. 40674058).

\section{References}

An M, Feng M, Dong S, Long C, Zhao Y, Yang N, Zhao W and Zhang J (2009a). Seismogenic structure around the epicenter of the May 12, 2008 Wenchuan earthquake from micro-seismic tomography. Acta Geologica Sinica (English Edition) 83(4): ): 724-732.

An M, Feng M and Long C (2009b). Deep ruptures around the hypocenter of the 2008 Wenchuan earthquake implied from aftershock observations. Tectonophysics (submitted).

Chen X Z, Lu X J and Wang H M (2001). $b$ value of the seismically active and quiescent periods and research of seismicty tendency in China's continent. Earthquake 21(1): 59-62 (in Chinese with English abstract).

Christensen N I (1996). Poisson's ratio and crustal seismology. J Geophys Res 101(B2): 3 139-3 156

Gutenberg B and Richter C F (1944). Frequency of earthquakes in California. Bull Seism Soc Amer 34(4): 185-188.

$\mathrm{Hu}$ X M (2007). Seismicity background around Zipingpu Dam before impounding. Earthquake Research in Sichuan (123): 18-23 (in Chinese with English abstract).

Lee W H K and Lahr J C (1972). HYPO71: A computer program for determining hypocenter, magnitude, and first motion pattern of local earthquakes. U.S. Geol Surv Open-File Rep, 100.

Mori J and Abercrombie R E (1997). Depth dependence of earthquake frequency-magnitude distributions in California: Implications for rupture initiation. $J$ Geophys Res 102(B7): 15 081-15090.

Richter C F (1958). Elementry Seismology. W H Freeman \& Co, San Francisco, California, 768

Scholz C H (1968). The frequency-magnitude relation of microfracturing in rock and its relation to earthquakes. Bull Seism Soc Amer 58(1): 399-415.

Scholz C H (2002). The Mechanics of Earthquakes and Faulting: 2nd edition. Cambridge University Press, New York, 496.

Tsapanos T M (1990). $b$-values of two tectonic parts in the circum-pacific belt. Pure Appl Geophys 134(2): 229-242.

Turcotte D L and Schubert G (2001). Geodynamics: 2nd edition. Cambridge University Press, Cambridge, UK, 528.

Vakov A V (1996). Relationships between earthquake magnitude, source geometry and slip mechanism. Tectonophysics 261(1-3): 97-113.

Wells D L and Coppersmith K J (1994). New empirical relationships among magnitude, rupture length, rupture width, rupture area, and surface displacement. Bull Seism Soc Amer 84(4): 974-1 002. 